\title{
The dimensional distortion of acrylic resin denture bases subjected to dual cure methods
}

MG Thokoane ${ }^{1}$, CP Owen ${ }^{2}$

\begin{abstract}
Introduction

Appropriatech is a philosophy under which methods have been proposed to reduce the number of visits necessary for procedures such as complete denture therapy, thereby reducing costs. One such method uses acrylic bases after the first visit which will require a subsequent dual cure which may produce distortion of the base.
\end{abstract}

Aim

To measure the three-dimensional distortion of different dual curing methods using the same resin.

\section{Methods}

A standardised maxillary denture base with teeth was created. Markers were set at different heights, to enable three-dimensional recordings, taken to an accuracy of $4 \mu \mathrm{m}$ using a reflex microscope. First, the teeth were set in wax on the clear acrylic heat-cured base, and the positions of the markers recorded. These bases were then subjected to a second processing, and measurements again taken. Four dual curing methods of varying temperatures and times were used.

\section{Results and conclusions}

All methods produced similar three-dimensional distortions of the denture base but the distortion was small, not affecting the fit or retention of the base. The most rapid method can therefore be used for a second cure onto an existing denture base.

Author affiliations:

1. Meriting G Thokoane: BDS, DPh, MDent., Specialist, Department of Prosthodontics, School of Oral Health Science, Faculty of Health Sciences, University of the Witwatersrand, Johannesburg, South Africa.

ORCID Number: 0000-0001-6820-0875

2. C Peter Owen: BDS, MScDent, MChD, FCD(SA), Professor Emeritus, Faculty of Health Sciences, University of the Witwatersrand, Johannesburg, South Africa.

ORCID Number: 0000-0002-9565-8010

Corresponding author: $\mathrm{C}$ Peter Owen

Professor Emeritus, Faculty of Health Sciences, University of the Witwatersrand, 7 York Road, Parktown, Johannesburg, South Africa. Email: peter.owen@wits.ac.za

Author contributions:

1. Meriting G Thokoane: Helped devise, and carried out the method and data gathering, and contributed to the writing - $70 \%$

2. C Peter Owen: Helped devise the method and contributed to the writing $-30 \%$
Keywords

Denture base, distortion, dual-cure, rapid-cure resins.

\section{INTRODUCTION}

Mucosa-borne complete dentures are the only treatment available for the majority of patients who cannot afford the alternatives of implant dentistry. Under the philosophy of Appropriatech, abbreviated methods have been proposed to reduce the number of visits necessary, thereby reducing costs. ${ }^{1}$

One such method ${ }^{2,3}$ uses acrylic bases after the first visit to record jaw relations, which are then retained as the final bases. This requires a second cure, which raises the potential for distortion of the base.

Previous dual-cure studies have reported distortions that would not be clinically significant. However, they all involve long curing times ${ }^{4-7}$ which increase time and costs; if shorter curing cycles could be used, this would be an advantage in many circumstances.

No studies could be found which tested the newer rapid-cure acrylic resins, so this study aimed to establish the distortion from a dual cure, using the same resin but different processing methods.

\section{MATERIALS AND METHODS}

Forty heat-cured denture bases were made from casts poured from a single mould. Each base was processed (Sure Acrylic Clear, Kemdent, Swindon, UK) by the same person, using a standard protocol.

After de-flasking and finishing, each denture base had an identical arch of teeth waxed onto it using a standardised mould, and incorporating dowel pins (Pindex, Dentaurum Sweden) in predetermined positions (Fig 1). The brass dowel pins were from a single batch, of a standard size, shape and surface anatomy and were serrated to prevent dislodgement.

The methods used for the second cure are shown in Table 1. All except the first have been shown to be associated with reduced distortion.4-6 Ten bases per method were used: sample size calculations had shown that at $80 \%$ power at the $5 \%$ significance level, sample sizes of 3-9 were required to detect large to moderate effect sizes. ${ }^{8}$ 
The same point on each pin was measured using a Reflex Microscope (Consultantnet Ltd, Cambridge, UK), which measures in three dimensions to an accuracy of $4 \mu \mathrm{m},{ }^{9}$ and which has been used successfully to measure the 3D distortion of frameworks. ${ }^{10}$ The following measurements were made:

1. After waxing the teeth to the base and before flasking

2. Immediately after the second cure and deflasking, but before removing the base from the cast.

3. After removal of the base from its cast.

For each distortion measure, a one-way analysis of variance (SAS Institute Inc., 2002-2010, Cary, NC, USA) was conducted with method as the factor. Where the data did not meet the assumptions of this test, the Kruskal-Wallis test was used. Effect sizes were measured using Cohen's d.

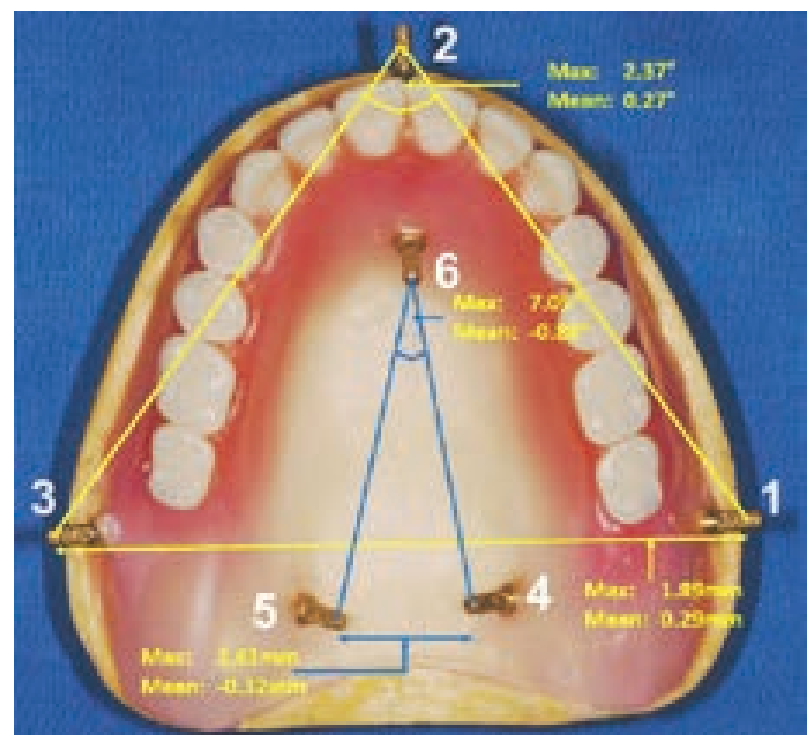

Figure 1. Graphical representation of the maximum and mean 3D changes for the differences between the waxed base and the cured base after deflasking.

\section{Table 1. Curing methods used for the second cure.}

\begin{tabular}{|c|c|}
\hline No. & Method \\
\hline 1. & $\begin{array}{l}\text { Place flask in boiling water for } 20 \text { minutes, remove and plunge } \\
\text { into cold water for } 20 \text { minutes }\end{array}$ \\
\hline 2. & $\begin{array}{l}\text { Place flask in cold water, allow the water to heat up to } 70^{\circ} \mathrm{C} \text { and } \\
\text { leave for } 1 \text { hour, remove and bench cool }\end{array}$ \\
\hline 3. & $\begin{array}{l}\text { Place flask in cold water. Allow water to heat up to } 72^{\circ} \mathrm{C} \text { and } \\
\text { leave for } 8 \text { hours and bench cool }\end{array}$ \\
\hline 4. & $\begin{array}{l}\text { Place flask in cold water, bring to boil for } 40 \text { minutes, bench cool } \\
\text { for } 45 \text { minutes, then plunged into cold water for } 20 \text { minutes }\end{array}$ \\
\hline
\end{tabular}

\section{RESULTS}

There were dimensional changes following the second cure for all curing methods. Measurements were converted to absolute percentage changes for statistical comparisons. Only two emerged as statistically significant.

The first was the absolute 3D change between the waxed base and the deflasked base: the distortion for Method 1 was higher than for Methods 2 and 4 (ANOVA: $p=0.0091$ ).
The effect sizes were large (Cohen's $d=1.2$ and 1.7 for Methods 2 and 4, respectively, vs. Method 1). The second was the 3D angular change formed by pins 5, 6 and 4 between the waxed base and the base after removal from the model (ANOVA $p=0.0032$ ); the distortion for Method 1 was higher than for Method 4. The effect size was large (Cohen's $d=2.3$ ).

The fact that only two significant differences were found means that it would be prudent to conclude that all methods produce similar distortion on balance and that therefore all methods are acceptable. Tables 2-4 show the mean absolute percentage 3D changes across all methods, and the mean and maximum actual changes for the differences between the waxed base and the final base. Fig 1 shows the maximum and mean changes graphically.

Table 2. Mean absolute percentage $3 D$ changes between the waxed
base and the cured base after deflasking.
\begin{tabular}{c|c|c|c} 
Pins 4 - 5 & Pins 1 - 3 & Angle 465 & Angle 123 \\
\hline $2.32 \%$ & $1.07 \%$ & $4.34 \%$ & $1.97 \%$ \\
\hline
\end{tabular}

\begin{tabular}{|c|c|c|c|}
\hline \multicolumn{4}{|c|}{ Dimension measured } \\
\hline Pins 4 - 5 & Pins 1 - 3 & Angle 465 & Angle 123 \\
\hline$-0.32 \mathrm{~mm}$ & $0.29 \mathrm{~mm}$ & $-0.86^{\circ}$ & $0.27^{\circ}$ \\
\hline
\end{tabular}

\begin{tabular}{|c|c|c|c|}
\hline \multicolumn{4}{|c|}{ Dimension measured } \\
\hline Pins 4 - 5 & Pins 1 - 3 & Angle 465 & Angle 123 \\
\hline $2.61 \mathrm{~mm}$ & $1.89 \mathrm{~mm}$ & $7.05^{\circ}$ & $2.37^{\circ}$ \\
\hline
\end{tabular}

\section{DISCUSSION}

The overall change between the base with teeth in wax and the final base removed from the flasked cast provides the most significant change from a clinical perspective. Although all distances and angles were measured, the prime concern was (a) posterior 3D change which may affect the palatal seal and (b) overall 3D distortion represented by the 3D angular measurements which could affect overall fit and retention.

The amount of distortion is important if the worst distortion is likely to affect the fit and retention of the denture base as well as the positions of the teeth. However, the maximum actual and percentage differences between the waxed base and the off-cast base are such that, in keeping with other studies, these would not be considered to be clinically significant.

\section{CONCLUSION}

All methods produced similar three-dimensional distortion of the denture base but the distortion was small and would not affect the fit or retention of the base. The most rapid method, which would save time and therefore money, can be used for a second cure onto an existing denture base. 


\section{References}

1. Owen PC. Appropriatech: Prosthodontics for the many, not just the few. Int J Prosthodont, 2004; 17: 261-2.

2. Owen CP, MacEntee M. The impact of socioeconomic, cultural, and technological changes and the notion of standards of care and alternative protocols. In: Zarb G, Hobkirk JA, Eckert SE, Jacob RF (Eds) Prosthodontic Treatment for the Edentulous Patient. 13 ${ }^{\text {th }}$ Ed. Elsevier Mosby, St Louis, 2012: 409-20.

3. Mengatto CM, Gameiro GH, Brondani M, Owen CP, MacEntee MI. A randomized controlled trial of mastication with complete dentures made by a conventional or an abbreviated technique. Int J Prosthodont. 2017; 30: 439-44.

4. Polukoshko KM, Brudvik JS, Nicholls JL, Smith DE. Evaluation of heat cured resin bases following addition of denture teeth using a second heat cure. J Prosthet Dent. 1992; 67: 556-62.

5. Yeung KC, Chow TW, Clark RFK. Temperature and dimensional changes in the two-stage processing technique for complete dentures. J Dent. 1995; 23: 245-53.

6. Polyzois GL, Karkazis HC, Zissis AJ, Demetriou PP. Dimensional stability of dentures processed in boilable acrylic resins: a comparative study. J Prosthet Dent. 1987; 57: 639-47.

7. Graser GN. Completed bases for removable dentures. J Prosthet Dent. 1978; 39: 232-6.

8. Faul F, Erdfelder E, Lang A-G, \& Buchner A. G*Power 3: A flexible statistical power analysis program for the social, behavioral, and biomedical sciences. Behavior Research Methods 2007; 39: 17591.

9. Scott PJ. The reflex plotters: measurement without photographs. Photogrammetric Record 1981; 10: 435-46.

10. Mitha T, Owen CP, Howes DG. The three-dimensional casting distortion of five-fixture-supported implant frameworks. Int J Prosthodont. 2009; 22: 248-50. 